\title{
New method of thermal cycling stability test of phase change material
}

\author{
Nandy Putra, ${ }^{1, *}$, Muhammad Amin, Rizky Achmad Luanto, Engkos A. Kosasih, Nasruddin A. Abdullah \\ Applied Heat Transfer Research Group Department of Mechanical Engineering Universitas Indonesia, 16424 Depok, Indonesia.
}

\begin{abstract}
Phase Change Material (PCM) is the most promising material as thermal energy storage nowadays. As thermal energy storage, examination on endurance of material for long-term use is necessary to be carried out. Therefore, thermal cycling test is performed to ensure thermal stability of PCM. This study have found a new method on thermal cycling test of PCM sample by using thermoelectric as heating and cooling element. RT $22 \mathrm{HC}$ was used as PCM sample on this thermal cycling test. The new method had many advantages compared to some references of the same test. It just needed a small container for PCM sample. The thermoelectric could release heat to PCM sample and absorb heat from PCM sample uniformly, respectively, was called as heating and cooling process. Hence, thermoelectric had to be supported by a relay control device to change its polarity so it could heat and cool PCM sample alternately and automatically. On the other hand, the thermoelectric was cheap, easy to be found and available in markets. It can be concluded that new method of thermal cycling test by using thermoelectric as source of heating and cooling can be a new reference for performing thermal cycling test on PCM.
\end{abstract}

\section{Introduction}

Phase Change Materials (PCMs) are materials which are mostly tested as thermal energy storage nowadays [1]. One of the advantages of PCM which have a high capacity in storing heat/cold because the contains the latent heat [2]. Meanwhile PCMs have also disadvantage, which has a low thermal conductivity [3]. In order to increase its themal conductivity, some researcher are adding nanoparticles into PCM $[4,5]$. The addition of nanoparticles can rise the rate of process in absorption and distribution of heat [6]. Unfortunatly, it can reduce the latent heat [7]. Therefore, thermal engineering is needed in process of mixing nanoparticles into PCM without reducing heat capacity of PCM. Mixing nanoparticle with PCM has been conducted by many researchers to increase latent heat $[8,9]$ and heat capacity [10].

If heat stored in PCM is used continuously (heating and cooling), the latent heat will decrease in certain time $[11,12]$. Hence, to find out the ability of PCM in storing heat for a long period, thermal cycling test is needed to performe. The objective of this test is to know the stability and realibity of PCM for long-term use [13]. The use of PCM in long-term is expected to be proper economically.

The process of thermal cycling test requires a particular measuring instrument that is well designed. The design of thermal cycling test has no standard, it just depends on the researchers themselves [14]. The test is expected that it can be operated continuously up to 1000 cycles. One cycle is equal to one process of heating and one process of cooling.

Basically, thermal cycling test utilizes heating and cooling element to release and absorb heat so it can be run continuously. Thermoelectric module that can provide hot and cold side can be applied as a new method as thermal cycling test of PCM. Thermoelectric module works as Peltier principle of heating and cooling $[15,16]$. The advantages of thermoelectric are simple, small dimension, light, and eco-friendly [17], able to heat and cool PCM in temperature ranges between 0 and $100{ }^{\circ} \mathrm{C}$.

The study about thermal cycling test were applied in different ways by some researchers. Sharma et al used hot plate as heating element for PCM, then allowed to cool at room temperature $[11,12,18]$. Shukla A et al utilized an oven that can be set at constant temperature to heat PCM. Then, it was taken out from the oven and allowed to cool at ambient temperature [19]. Sari A conducted thermal cycling test by using a thermostatic bath. It consisted of a heater which was used to heat PCM. For cooling process, heating controller was switched off and PCM was allowed to cool at ambient temperature [20]. Sharma A and Shukla A used two chambers that were filled by water, both of them was used, respectively, as source of heating and cooling for PCM [21]. Silakhori M et al utilized stainless steel heater which was sticked on a rectangular box that made of copper and filled by PCM sample to be heated. A heat pipe heat sink with fan was also sticked on that box to help the cooling process [22].

\footnotetext{
* Corresponding author: prayudi@sttpln.ac.id
} 
Based on some references, that thermal cycling test with thermoelectrics is not found. The objective of this study is to design a new method of thermal cycling test on PCM. This new method is predicted to have many advantages compared to recent method of some researchers.

\section{Methodology}

\subsection{Design Concept of Thermal Cycling Test Device}

In this research proposed a new thermal cycling test device that has been designed and shown in Fig 1. This new concept is that applied two thermoeletrics as source of heating and cooling. In order to have heating and cooling alternately to the PCM sample, this new design needs polarity switch to change the polarity of output voltage. A programmable DC power supply is connected to the device to trigger automatically. The others support on this device consist of 2 DC fans, heat sink, 2 clamps, 4 bolts, 4 nuts, 8 rings, DC adaptor. Fig 2 shows the overall layout of thermal cycling test device.
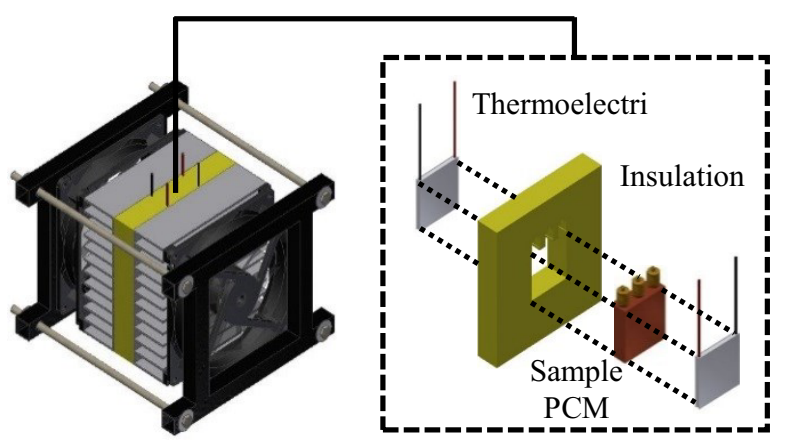

Fig. 1. The layout of thermal cycling test device.

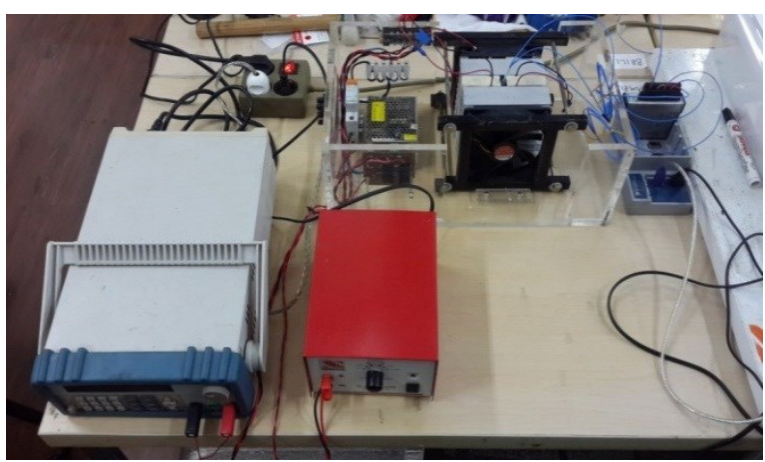

Fig. 2. Overall layout of thermal cycling test device.

In Fig 3 shows the installation process of thermal cycling test device. PCM is poured into cartridge that made of copper with dimension $40 \times 40 \times 14 \mathrm{~mm}$. PCM cartridge is made by preparing $0.8 \mathrm{~mm}$ copper plate. It is formed into 6 sides, then it is connected by welding. The top side of cartridge is given with 3 nipples for the way in and out of PCM sample that will be tested on its thermal cycle. The middle nipple is also used as the access of thermocouple into PCM cartridge. The side of PCM cartridge is isolated in order to avoid heat lose to surroundings when thermal cycling test is operating for heating and cooling. Polyurethane that has low thermal conductivity is used for insulation system. It has dimension of $120 \times 22 \times 120 \mathrm{~mm}$ with hole in the center. The hole is adapted with dimension of PCM cartridge so it can enter into the insulation. Two thermoelectrics are installed on this thermal cycling test with dimension $40 \mathrm{x}$ $40 \mathrm{~mm}$. It have a specification of $12 \mathrm{~V}$ and $5 \mathrm{~A}$. Heat sink is used in order to thermoelectric is not easily damaged. It is made of aluminium with dimension $120 \mathrm{x}$ $35 \times 120 \mathrm{~mm}$. It has 12 fins with the thickness of 2.5 $\mathrm{mm}$. All of those parts can be purchased cheaply and are able to be used continuously in particular to test thermal cycle of PCM.
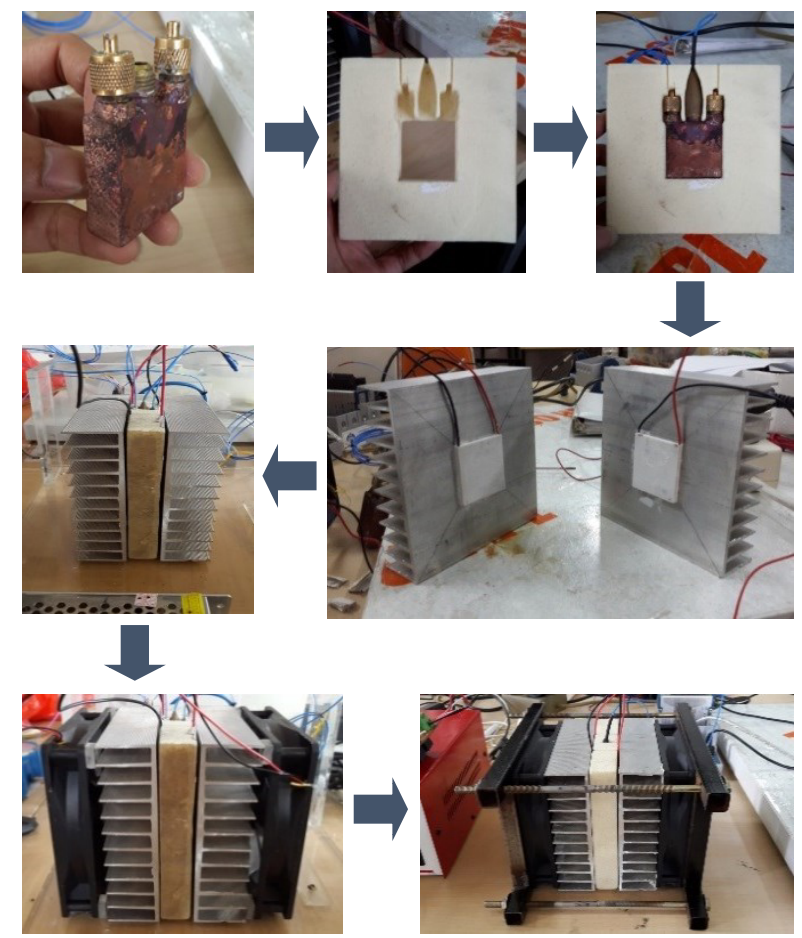

Fig. 3. Installation process of thermal cycling test device.

\subsection{Thermal Cycling Test}

In this study, sample of PCM RT $22 \mathrm{HC}$ is used and It was purchased from Rubitherm Technologies $\mathrm{GmbH}$. Thermal cycling test device is operated in this study until 1000 cycles. The amount of those cycles are similar to the research of Silakhori M et al [22]. In Fig 4 shows the schematic of thermal cycling test. The procedures of this study are fully outlined as follows: firstly the sample is poured into PCM cartridge with mass of 12 grams. The thermocouples are attached in PCM cartridge. PCM cartridge is placed into hole center of polyurethane insulation which is already formed. Installed two thermoelectric on both side of PCM cartridge. Make sure two thermocouples are fitted between PCM cartridge and thermoelectric. Stick two heat sinks on both of thermoelectric. Installed two DC fans on both of heat sink fins. Installed two clamps on both of the outside of DC fans and tightened those two clamps with bolts, nuts 
and rings. Voltage of polarity switch with $12 \mathrm{~V}$ is connected to adaptor. Trigger voltage of polarity switch is connected to programmable DC power supply. Connected thermoelectric with output voltage of polarity switch and connected DC fan with 10 Ampere DC adaptor. Connected thermocouples that already installed on their spots with NI cDAQ 9174 and connected NI cDAQ 9174 with NI 9211. Set voltage on 10 A DC adaptor with $12 \mathrm{~V}$ and turned on $\mathrm{DC}$ fan. Set voltage on programmable DC power supply with 0 and $3 \mathrm{~V}$ that changed alternately. Time set for $0 \mathrm{~V}$ is 420 seconds ( 7 minutes) and time set for $3 \mathrm{~V}$ is 180 seconds ( 3 minutes). The voltage of $0 \mathrm{~V}$ is for cooling and $3 \mathrm{~V}$ is for heating. Turned on thermoelectric with activating of $12 \mathrm{~V}$ adaptor and programmable DC power supply. Recorded the thermocouple readings through computer.



Fig. 4. Schematic of thermal cycling test.

Fig 5 shows the installation of thermocouples in PCM cartridge and in the wall of PCM cartridge (between PCM cartridge and thermoelectric). In this study, one thermocouple is installed in PCM cartridge, two thermocouples are installed between PCM cartridge and thermoelectric. Installation of thermocouple in PCM cartridge is to know the temperature of PCM samples when they are melting and freezing. Installation of thermocouple between PCM cartridge and thermoelectric is to know the temperature of thermoelectric when it is heating and cooling.


Fig. 5. Installation of thermocouples.

\section{Analysis and Discussion}

\subsection{Results of Thermal Cycling of PCM RT 22 HC Thermoelectric Base}

In Fig 6 shows the temperature distribution of thermal cycling test of PCM with sample of RT $22 \mathrm{HC}$. The thermal cycle device is operated for 300, 500, 700 and 1000 cycles. The process of heating and cooling ran for 7 minutes and for 3 minutes respectively. During the process, there are some phenomenon. When thermoelectric worked as cooling, sample starts to undergo the process of freezing. There are horizontal lines (near constant temperature) known as a process whereby the sample is changing phase. Then, when thermoelectric changes its function to heat up, temperature of sample will increase followed by the increase of thermoelectric temperature. It is caused by a lack of cooling time that is given to the sample so that phenomena appeared.

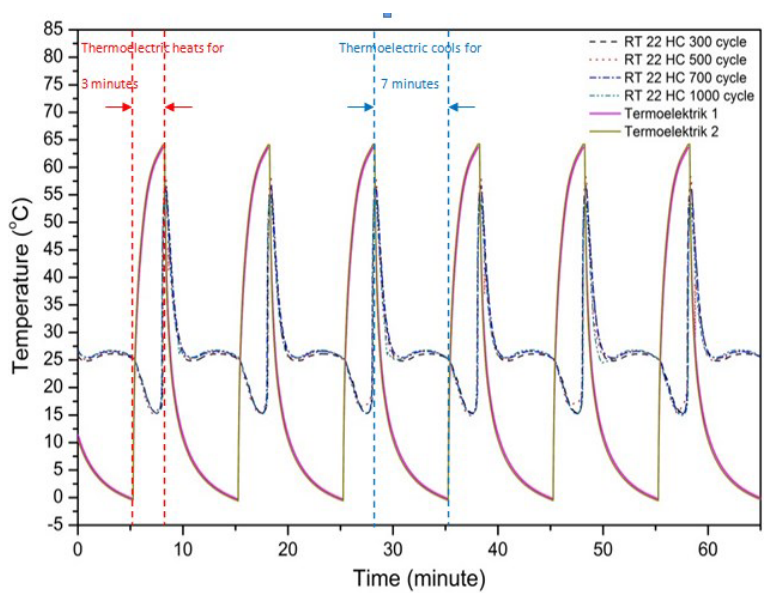

Fig. 6. The result of thermal cycling test of PCM with sample of RT $22 \mathrm{HC}$.

Table 1. Thermal properties of RT $22 \mathrm{HC}$ after 0,500 and 1000 cycles (melting).

\begin{tabular}{|c|c|c|}
\hline $\begin{array}{c}\text { Number of cycle } \\
(\mathbf{s})\end{array}$ & $\begin{array}{c}\text { Latent heat of } \\
\text { fusion }(\mathbf{J} / \mathbf{g})\end{array}$ & $\begin{array}{c}\text { Melting point } \\
\left({ }^{\circ} \mathbf{C}\right)\end{array}$ \\
\hline 0 & 163.31 & 25.37 \\
\hline 500 & 196.80 & 25.08 \\
\hline 1000 & 169.62 & 25.11 \\
\hline
\end{tabular}

Table 2. Thermal properties of RT $22 \mathrm{HC}$ after 0,500 and 1000 cycles (freezing).

\begin{tabular}{|c|c|c|}
\hline $\begin{array}{c}\text { Number of cycle } \\
(\mathbf{s})\end{array}$ & $\begin{array}{c}\text { Latent heat of } \\
\text { fusion }(\mathbf{J} / \mathbf{g})\end{array}$ & $\begin{array}{c}\text { Melting point } \\
\left({ }^{\circ} \mathbf{C}\right)\end{array}$ \\
\hline 0 & 169.02 & 19.11 \\
\hline 500 & 204.83 & 18.86 \\
\hline 1000 & 177.29 & 18.90 \\
\hline
\end{tabular}

The placement of thermocouple was located in the middle of sample in PCM to monitor the change of temperature, when the surface temperature of thermoelectric increases significantly, temperature of PCM still low and frozen. This is caused by the placement of thermocouple at the middle of sample, 
Heat from thermoelectric needs time to reach the center of sample.

From the temperature measurement, there is no difference in measured temperature between 300, 500, 700 and 1000 cycles when sample undergo the process of heating and cooling. It proves that heat given by both thermoelectrics at each cycles are uniform, so the obtained data will be more accurate.

The latent heat of fusion and melting point of RT 22 $\mathrm{HC}$ after 0, 500 and 1000 cycles (melting and freezing point) were measured by Differential Scanning Calorimetry (DSC) and summarized in Table 1 and Table 2. Based on the results, the latent heat of fusion and melting point did not change significantly up to 1000 cycles. So, it is necessary retested more 1000 cycle to have the change in thermal properties of RT $22 \mathrm{HC}$.

\subsection{The Comparison of Method of Thermal Cycling Test Device}

Some methods of thermal cycling test device of PCM from the other researchers as comparison will be discussed.

Mehrali $\mathrm{M}$ et al create a thermal cycling test device of PCM as shown in Fig 7 [23]. This device have disadvantage compared to thermal cycling test device based on thermoelectric. The temperature range Mehrali's device can operate from $30{ }^{\circ} \mathrm{C}$ to $80{ }^{\circ} \mathrm{C}$ while the device based on thermoelectric can operate from 0 ${ }^{\circ} \mathrm{C}$ to $100{ }^{\circ} \mathrm{C}$. This device uses fan for cooling PCM. The time for cooling PCM on this device is longer than on thermal cycling test device based on thermoelectric. The device based on thermoelectric need only 7 minutes for cooling PCM.

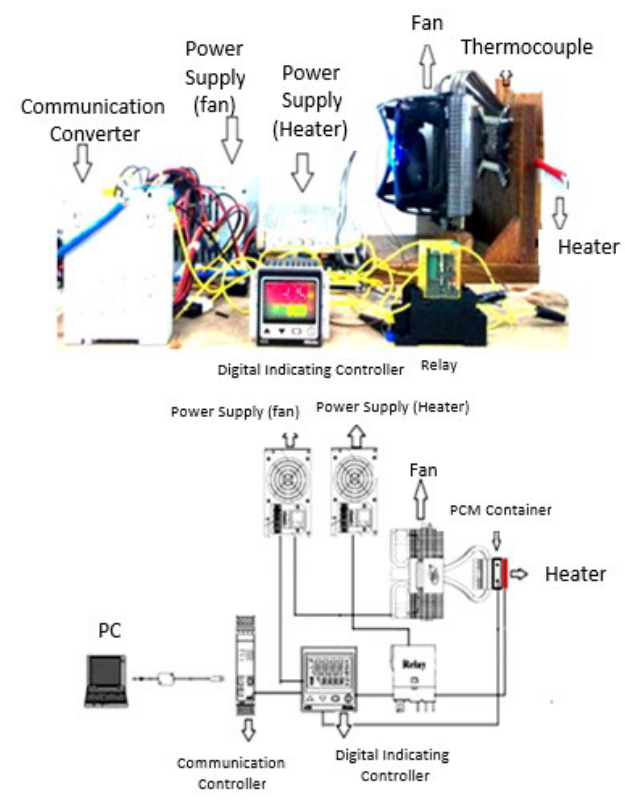

Fig. 7. Design of thermal cycling test device by Mehrali M et al [23].

Atul Sharma and A. Shukla proposed a thermal cycling test device of PCM using two water baths as shown in Fig 8 [21]. This device has disadvantage that is too complicated, needs large space and high cost. The process of cooling PCM is conducted by allowing PCM in cold water bath which its temperature has set. From both of comparison above, the purposed thermal cycling test device of PCM based on thermoelectric has advantages such as simple, easy to be moved, light, lowcost, taking more accurate data, and can be set from low to high temperature. This thermal cycling test device can be used continuously and be a new method for testing thermal stability of PCM.

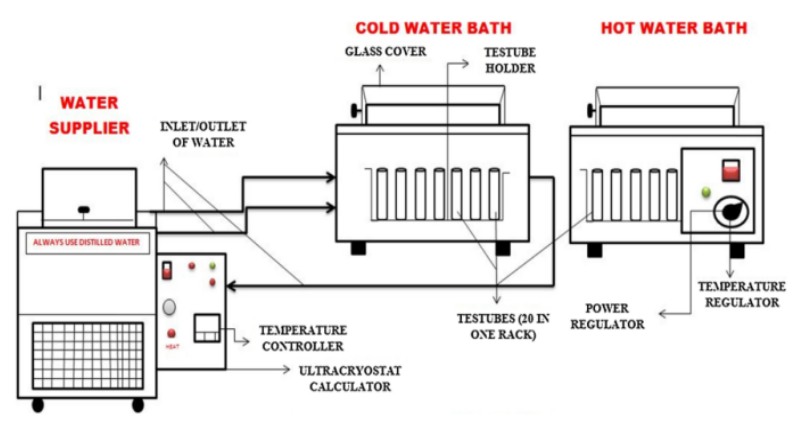

Fig. 8. Design of thermal cycling test device by A. Sharma and A. Shukla [21].

\section{Conclusion}

In this study, a new method has been proposed to obtained thermal stability by using thermal cycling test device based on thermoelectric. It has advantages such as simple, easy to be moved, light, low cost, taking more accurate data, can be set from low to high temperature. Heat released from thermoelectric on thermal cycling test are uniform at each cycles when it undergo the process of heating and cooling. The latent heat of fusion and melting point did not change significantly up to 1000 cycles.

The authors would like to thank KEMENRISTEK DIKTI and DRPM University of Indonesia for funding this research.

\section{References}

1. Zalba B, Marín JM, Cabeza LF, Mehling H.. Applied thermal engineering (2003),23:251-283.

2. Tatsidjodoung P, Le Pierrès N, Luo L. Renewable and Sustainable Energy Reviews (2013),18:327349.

3. Pincemin S, Olives R, Py X, Christ M. Solar Energy Materials and Solar Cells (2008),92:603613.

4. Prasher RS, Chang J-Y, Sauciuc I, Narasimhan S, Chau D, Chrysler G, et al. Intel Technology Journal (2005),9.

5. Saleh R, Putra N, Wibowo RE, Septiadi WN, Prakoso SP. Experimental Thermal and Fluid Science (2014),52:19-29.

6. Putra N, Prawiro E, Amin M.. International Journal Of Technology (2016), 7:244-253.

7. Yuan Y, Zhang N, Li T, Cao X, Long W. Thermal 
performance enhancement of palmitic-stearic acid by adding graphene nanoplatelets and expanded graphite for thermal energy storage: A comparative study. Energy (2016),97:488-497.

8. Amin M, Putra N, Kosasih EA, Prawiro E, Luanto RA, Mahlia TMI. Applied Thermal Engineering (2017),112:273-280.

9. Şahan N, Fois M, Paksoy H. Solar Energy Materials and Solar Cells (2015),137:61-67.

10. Chieruzzi M, Cerritelli GF, Miliozzi A, Kenny JM. Nanoscale research letters (2013),8:1.

11. Sharma S, Buddhi D, Sawhney R. Accelerated thermal cycle test of latent heat-storage materials. Solar Energy (1999),66:483-490.

12. Sharma A, Sharma S, Buddhi D. Energy Conversion and Management (2002),43:19231930.

13. Pielichowska K, Pielichowski K. Phase change materials for thermal energy storage. Progress in Materials Science (2014),65:67-123.

14. Ferrer G, Solé A, Barreneche C, Martorell I, Cabeza LF. Review on the methodology used in thermal stability characterization of phase change materials. Renewable and Sustainable Energy Reviews (2015),50:665-685.

15. He W, Zhou J, Hou J, Chen C, Ji J. Theoretical and experimental investigation on a thermoelectric cooling and heating system driven by solar. Applied Energy (2013),107:89-97.

16. Putra N, Ardiyansyah, Sukyono W, Johansen D, Iskandar FN. The characterization of a cascade thermoelectric cooler in a cryosurgery device. Cryogenics (2010),50:759-764.

17. Djafar Z, Putra N, Koestoer RA. The Utilization of Heat Pipe on Cold Surface of Thermoelectric with Low-Temperature Waste Heat. In: Applied Mechanics and Materials: Trans Tech Publ; (2013). pp. 410-415.

18. Raam Dheep G, Sreekumar A. Energy Conversion and Management (2015),105:13-19.

19. Shukla A, Buddhi D, Sawhney R. Renewable Energy (2008),33:2606-2614.

20. Sar1 A. Thermal reliability test of some fatty acids as PCMs used for solar thermal latent heat storage applications. Energy Conversion and Management (2003),44:2277-2287.

21. Sharma A, Shukla A. Energy and Buildings (2015),99:196-203.

22. Silakhori M, Naghavi MS, Metselaar HSC, Mahlia TMI, Fauzi H, Mehrali M. Materials (2013),6:1608-1620.

23. Mehrali M, Latibari ST, Mehrali M, Metselaar HSC, Silakhori M. Energy Conversion and Management (2013),67:275-282. 